\title{
Indocyanine Green Videoangiography of Optic Cavernous Angioma -Case Report-
}

\author{
Yasuo MURAI, ${ }^{1}$ Koji ADACHI, ${ }^{1}$ Kenta KOKETSU, ${ }^{1}$ and Akira TERAMOTO ${ }^{1}$ \\ ${ }^{1}$ Department of Neurosurgery, Nippon Medical School, Tokyo
}

\begin{abstract}
The intraoperative findings of an indocyanine green videoangiography (ICG-VAG) study of a cavernous angioma located in the optic chiasm are reported. A 23-year-old Japanese man suddenly developed visual field loss, and magnetic resonance imaging suggested the presence of a suprasellar tumor in contact with the optic chiasm. Preoperative angiography did not clearly show any tumor shadow. Right fronto-temporal craniotomy was performed, and an aggregation of blood vessels was seen on the right surface of the optic chiasm. Cavernous angioma was suspected. ICG-VAG was begun 22 seconds after the beginning of contrast agent infusion via a peripheral blood vessel. The lesion remained unstained, although the brain surface, an artery superior to the optic nerve, and veins were visualized. The cavernous angioma was resected following surface coagulation. ICG-VAG is currently being evaluated for future application in the differential diagnosis based on imaging findings, and the present case provides an important example of intraoperative ICG-VAG imaging of an unoperated cavernous angioma.
\end{abstract}

Key words: angiography, cavernous angioma, indocyanine green, optic chiasm, tumor

\section{Introduction}

Indocyanine green videoangiography (ICG-VAG) has been used as a tool for intraoperative monitoring since about $2000,{ }^{8,11,13)}$ and is particularly useful during the neurosurgical treatment of vascular disorders. ${ }^{8,11,13,18)}$ ICG-VAG was reported as an intraoperative diagnostic imaging technique for evaluating cerebral perfusion in 2003. ${ }^{11)}$ Subsequently, ICG-VAG has been developed as an easy, rapid, and inexpensive modality. ICG-VAG can confirm aneurysm occlusion, residual blood flow through perforators of approximately $0.3 \mathrm{~mm}$ in diameter, and patency of reconstructed blood vessels. ${ }^{8,11,13,18)}$ ICG-VAG is useful in cases of aneurysm, vascular reconstruction, and cerebral infarction, ${ }^{1-4)}$ and also in some patients with tumorous lesions. ${ }^{1,5,8,9,11,13,18)}$ In comparison with cerebral angiography, which is a radiographic procedure, ICG-VAG is a fluorescence imaging method and cannot ${ }^{8,11,13,18)}$ depict the lesion site if the irradiated light is blocked by the brain parenchyma or skin. Therefore, a lesion in the brain parenchyma can only be observed if the perilesional tissue is first removed. ${ }^{5,8)}$ However, procedures such as coagulation, compression, or ablation around the lesion may affect the lesion and/or the imaging findings, so affecting any objective evaluation of the lesion. ${ }^{5,8,11,18)}$ Since cavernous angiomas are usually located in the brain parenchyma, ${ }^{15-17,19)}$ ICG-VAG images of cavernous angioma that are unaffected by surgical procedures are com-

Received June 17, 2010; Accepted September 10, 2010 paratively rare. ${ }^{5)}$

We recently obtained ICG-VAG findings of an optic chiasmal cavernous angioma without removal of the perilesional tissues because of the location on the surface of the optic nerve.

\section{Case Presentation}

A 23-year-old Japanese man suddenly developed visual field loss (tunnel vision). $\mathrm{T}_{1}$-weighted magnetic resonance (MR) imaging suggested the presence of a suprasellar tumor (Fig. 1), and surgical treatment was selected. $\mathrm{T}_{1-}$ weighted MR imaging with gadolinium revealed a partially enhanced lesion in contact with the optic chiasm. $\mathrm{T}_{2^{-}}$ weighted MR imaging was not obtained. Preoperative angiography did not show any clear tumor shadow. These findings suggested craniopharyngioma or pituitary adenoma.

A right transsylvian approach revealed aggregation of blood vessels on the right surface of the optic chiasm (Fig. 2), and a cavernous angioma was suspected. ICG $10 \mathrm{mg} / \mathrm{kg}$ (25 mg/10 ml of distilled water) was intravenously infused via a peripheral blood vessel, flushing was performed with $10 \mathrm{ml}$ of physiological saline, and arterial visualization was obtained from 22 seconds after the beginning of ICG infusion. The lesion above the optic nerve was not stained in either the arterial or the venous phases (Fig. 3). Imaging was performed for approximately 3 minutes after the start of contrast agent infusion, but no changes in this avascular area were observed (Fig. 4). Following surface coagula- 


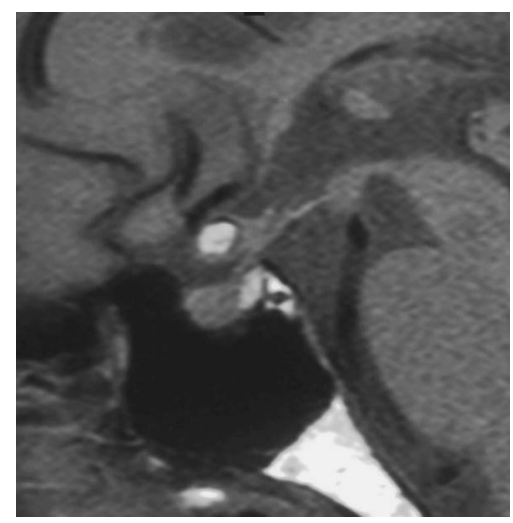

Fig. 1 Preoperative $T_{1}$-weighted magnetic resonance image of a tumorous region in the optic chiasm appearing as a prominent heterogeneous high intensity region.

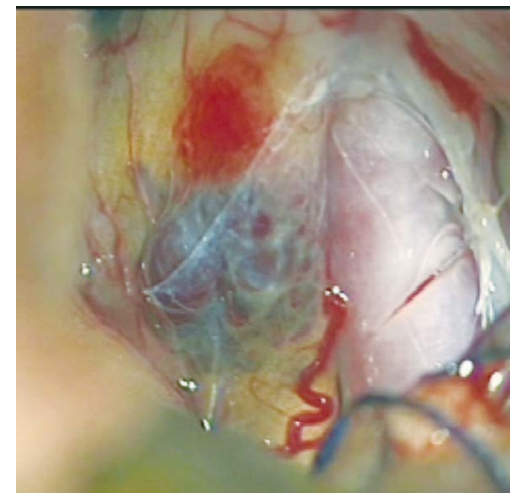

Fig. 2 Intraoperative photograph of a cavernous angioma located on the right optic chiasm via the right pterional approach.

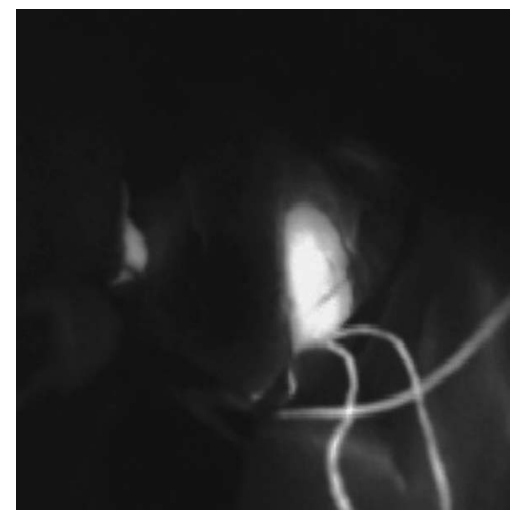

Fig. 3 Indocyanine green videoangiography image taken 22 seconds after the beginning of contrast agent infusion showing the internal carotid artery is distinctly stained, whereas the cavernous angioma appears as an avascular area.

tion, the cavernous angioma was removed by peeling away from the optic nerve surface.

Histological examination of the specimen revealed ir-

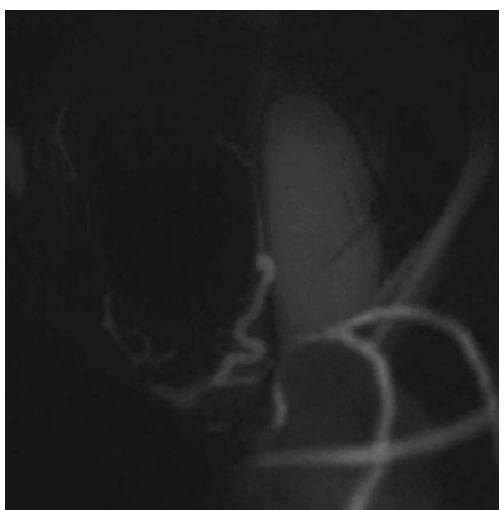

Fig. 4 Indocyanine green videoangiography image taken 187 seconds after the beginning of contrast agent infusion showing a decrease in the delineation of the internal carotid artery, and visualization of the veins on the brain surface, but the hematoma continues to appear as an avascular area.

regular vascular spaces containing blood elements, lined by a single layer of endothelial cells. The vascular walls consisted of hyalinized collagen that was partly calcified. The histological diagnosis was cavernous angioma.

Postoperatively, neither visual field nor visual acuity had deteriorated, and the patient was discharged on the 10th postoperative day.

\section{Discussion}

Intraoperative ICG-VAG study of a cavernous angioma located in the optic chiasm showed that the lesion remained unstained, although the brain surface, an artery superior to the optic nerve, and the veins were all visualized. Cavernous angioma located on the brain surface or the surface of the optic nerve is very rare, ${ }^{2-4,7,12)}$ so the present study represents the unusual ICG-VAG findings of an unoperated lesion.

In the present case, the cavernous angioma was depicted as an avascular area, similar to the usual findings with cerebral angiography. ${ }^{6,15-17,19)}$ Cerebral angiography usually detects no abnormalities in patients with cavernous angioma, although occasional abnormal angiographic findings include widened draining vein, capillary blush or stain, and evidence of neovascularity. ${ }^{6,15-17,19)}$ Some cases of optic nerve cavernous angiomas have shown similar angiographic findings to intraparenchymal cavernous angioma. ${ }^{2-4,7,10)}$ Cerebral angiography is inadequate for the diagnosis of cavernous angiomas because of the small size of the feeding arteries, the slow circulation, and the frequent presence of thrombi within the vascular spaces. ${ }^{14,15)}$ For the same reasons, ICG-VAG detected no fluorescence in this case. ICG-VAG of three cases of intraparenchymal cavernous angiomas found no fluorescence in any of the cavernous malformations or associated venous anomalies. 5) These findings may be useful in the intraoperative differential diagnosis, but experience of more such cases is required. ICG-VAG is currently being evaluated for future application in the differential diagnosis based on im- 
aging findings, and the present case provides an important example of intraoperative ICG-VAG imaging of an unoperated cavernous angioma.

\section{References}

1) Bonnet M: Cavernous hemangioma of the choroid. Clinical review of 10 cases. Ophthalmologica 182: 113-118, 1981

2) Elmaci I, Ates G, Kurtkaya O, Necmettin Pamir M: Chiasmal cavernous malformation. A rare cause of acute visual loss. J Neurosurg Sci 44: 226-229, 2000

3) Hempelmann RG, Mater E, Schröder F, Schön R: Complete resection of a cavernous haemangioma of the optic nerve, the chiasm, and the optic tract. Acta Neurochir (Wien) 149: 699-703, 2007

4) Iwai Y, Yamanaka K, Nakajima H, Miyaura T: Cavernous angioma of the optic chiasm-case report. Neurol Med Chir (Tokyo) 39: 617-620, 1999

5) Khurana VG, Seow K, Duke D: Intuitiveness, quality and utility of intraoperative fluorescence videoangiography: Australian Neurosurgical Experience. Br J Neurosurg 24: 163172,2010

6) Maraire JN, Awad IA: Intracranial cavernous malformations: lesion behavior and management strategies. Neurosurgery 37: 591-605, 1995

7) Mohr G, Hardy J, Gauvin P: Chiasmal apoplexy due to ruptured cavernous hemangioma of the optic chiasm. Surg Neurol 24: 636-640, 1985

8) Murai Y, Adachi K, Koketsu K, Teramoto A: [Noninvasive measurement of cortical blood flow by microscope-integrated intraoperative indocyanine green videoangiography]. No Shinkei Geka Journal 18: 839-843, 2009 (Japanese)

9) Murai Y, Adachi K, Matano F, Tateyama K, Teramoto A: Indocyanin green videoangiography study of hemangioblastomas. Can J Neurol Sci 38: 41-47, 2011

10) Newman H, Nevo M, Constantini S, Maimon S, Kesler A: Chiasmal cavernoma: a rare cause of acute visual loss improved by prompt surgery. Pediatr Neurosurg 44: 414-417, 2008

11) Raabe A, Beck J, Gerlach R, Zimmermann M, Seifert V:
Near-infrared indocyanine green video angiography: a new method for intraoperative assessment of vascular flow. Neurosurgery 52: 132-139, 2003

12) Regli L, de Tribolet N, Regli F, Bogousslavsky J: Chiasmal apoplexy: haemorrhage from a cavernous malformation in the optic chiasm. J Neurol Neurosurg Psychiatry 52: 10951099, 1989

13) Sakatani K, Kashiwasake-Jibu M, Terada H, Zuo H: Development of surgical confocal scanning microscope for intraoperative imaging of brain tumors using near infrared fluorescence: technical note. Neurol Res 22: 533-536, 2000

14) Savoiardo M, Strada L, Passerini A: Intracranial cavernous hemangiomas: neuroradiologic review of 36 operated cases. AJNR Am J Neuroradiol 4: 945-950, 1983

15) Servo A, Porras M, Raininko R: Diagnosis of cavernous haemangiomas by computed tomography and angiography. Acta Neurochir (Wien) 71: 273-282, 1984

16) Steinberg GK, Baskaya MK, Saito K, Suzuki Y, Ooka K, Hara $\mathrm{M}$ : Cavernous malformations of the optic chiasma. Acta Neurochir (Wien) 136(1-2): 29-36, 1995

17) Steinberg GK, Marks MP, Shuer LM, Sogg RL, Enzmann DR, Silverberg GD: Occult vascular malformations of the optic chiasm: magnetic resonance imaging diagnosis and surgical laser resection. Neurosurgery 27: 466-470, 1990

18) Takagi Y, Kikuta K, Nozaki K, Sawamura K, Hashimoto N: Detection of a residual nidus by surgical microscope-integrated intraoperative near-infrared indocyanine green videoangiography in a child with a cerebral arteriovenous malformation. J Neurosurg 107(5 Suppl): 416-418, 2007

19) Tomlinson FH, Houser OW, Scheithauer BW, Sundt TM Jr, Okazaki H, Parisi JE: Angiographically occult vascular malformations: a correlative study of features on magnetic resonance imaging and histological examination. Neurosurgery 34: 792-800, 1994

Address reprint requests to: Yasuo Murai, MD, Department of Neurosurgery, Nippon Medical School, 1-1-5 Sendagi, Bunkyo-ku, Tokyo 113-8603, Japan.

e-mail:ymurai@nms.ac.jp 